\title{
ASPECTOS ULTRA-ESTRUTURAIS DA FORMA EPIMASTIGOTA DO TRYPANOSOMA CRUZI EM MEIO LIT
}

\author{
Wanderley de Souza, * Noemia Grynberg * * F. Nery-Guimarães * *(1)
}

\begin{abstract}
E feito um estudo da ultra-estrutura da forma epismastigota do Trypanosoma cruzi mantida em meio de cultivo acelular.

o núcleo das formas em divisão apresenta um aspecto homogêneo. Microtúbulos intranucleares são observados durante a divisão. No entanto, a membrana nuclear permanece integra.

o citoplasma apresenta-se com vacúolos de dimensōes e aspectos variados.

Com o método do ácido periódico-tiosemicarbazida-proteinato de prata, polissacarideos elou glicoproteinas foram localizados na membrana celular e na membrana que delimita certos vacúolos citoplasmáticos.
\end{abstract}

\section{INTRODUÇÃO}

A ultra-estrutura do Trypanosoma cru$z i$ tem sido objeto de estudo por vários pesquisadores $(3,6,7,9,11,12,13-19,21$, $24-28,32$ ). No entanto várias dúvidas ainda não foram completamente dissipadas quanto às características morfológicas $\mathrm{e}$ funcionais das várias estruturas celulares existentes neste protozoário .

A forma epimastigota do $T$. cruzi representa até o momento a única forma facilmente cultivável em meios acelulares o que permite a obtençãs de grandes quantidades de parasitos facilitando a realização de estucios bicquímicos. Por este motivo escolhemos esta forma para realizarmos uma série de estudos citoquímicos com microscopia eletrônica, cujos resulta- dos poderão ser correlacionados com dados de natureza bioquímica.

Neste trabalho ciescrevemos aspectos gerais da ultra-estrutura do T. cruzi crescendo em meio LIT, dando ênfase especial aos vacúolos citoplasmáticos.

\section{MATERIAL E MÉTODOS}

Neste estudo utilizamos a cepa $Y$ (22) do Trypanosoma cruzi crescendo a $28^{\circ} \mathrm{C}$ em meio LIT (5) .

Foram estuciadas células de culturas com 3,5 e 7 dias de cultivo. As células foram fixadas em glutaraldeido $2,5 \% \mathrm{em}$ tampão cacodilato ou fosfato $0,1 \mathrm{M} \mathrm{pH} \mathrm{7,4}$ durante 1-2 horas a $4^{\circ} \mathrm{C}$ ou a temperatura ambiente. Após fixação as células eram lavadas em tampão, pós-fixadas em $0 \mathrm{s0}_{4} \quad 1 \%$

Laboratório de Microscopia Eletrônica, Instituto de Biofísica U.F.R.J., Cidade Universitária, Rio de Janeiro - RJ.

** Laboratório de Protozoolcgia, Instituto Oswaldo Cruz, Rio de Janeiro - RJ.

1 Lamentamos informar o falecimento do Prof. F. Nery-Guimarães em 15-4-1975. A sua amizade e a maneira com que se dedicava à investigação científica ficarão para sempre na memória de tndos aqueles que com ele conviveram.

Recebido para publicação em 21.5.1975. 
em tampāo fosfato $0,1 \mathrm{M} \mathrm{pH} 7,4$ curante 1 hora a $4^{\circ} \mathrm{C}$, desidratadas em etanol ou acetona e incluidas em epon. Cortes ultrafinos foram obtidos com ultramicrótomo LKB Ultratome III e contrastados em citrato de chumbo e acetona de uranila. $\mathrm{Pa}$ ra estudo citoquímico os cortes foram coletacios em grades de ouro e submetidos ao método de Thiéry (30) tal como descrito em trabalhos anteriores (7-10). As telas foram examinadas com o microscópio eletrônico AEI, EM6-B.

\section{RESULTADOS E DISCUSSÃO}

As características básicas apresentadas pela forma epimastigota do T. cruzi mantido em meio LIT são semelhantes às descrita anteriormente em outros estágios evolutivos deste protozoário $(3,6,7,9,11$, 12, 13-19, 21, 24-28, 32).

Apresenta um núcleo que se localiza na regiāo central. No estacio interfásico este núcleo apresenta uma estrutura semelhante àquela observada com as formas intracelulares (6). O material cromatínico se dispōe principalmente na periferia podendo no entanto ser encontrado na região central. O nucléolo ocupa uma posição central ou ligeiramente excêntrica (Fig. 1). O núcleo de uma célula em divisão, à semelhança do que ocorre com as formas esferomastigotas (amastigota, leishmania) observadas em cultura de tecidos (6), apresenta um aspecto uniforme, resultante da dispersão do material cromatínico e nucleolar (Fig. 2). Uma característica básica destes núcelos é a existência de microtúbulos que se dispõem longitudinalmente no sentido de alongamento do núcleo No interior do núcleo se observam algumas estruturas eletrodensas cuja natureza ainda não está esclarecida (Fig. 2). Possivelmente representam fragmentos do nucléolo ou estruturas que correspondam a cromossomos. Estudos autoraciográficos, citoquímicos e digestão enzimática poderão esclarecer melhor a natureza desta estrutura.

Nem todos os perfis de núcleos que apresentam um aspecto uniforme (que utilizamos como critério para identificar uma célula em divisão) mostram microtúbulos intranucleares, devido a localização dos microtúbulos na parte central do núcleo. Tal fato torna-se bastante claro quando se examinam cortes seriados.
Uma outra caracteristica importante na divisão do núcleo do $T$. cruzi é a ausência de centríolo ou placa eletrodensa nos polos do núcleo e a permanência da mem brana nuclear. O mesmo ocorre com as formas intracelulares em cultura de tecidos (6) bem como em $T$. rhodesiense e $T$. raiae (31).

O cinetroplasto apresenta uma estrutura semelhante à descrita para formas intracelulares (Figs. 1 e 3). O flagelo apresenta um axonema típico e se caracteriza por apresentar uma estrutura paraflagelar constituída por filamentos dispostos em um arranjo regular, cujo papel funcional ainda não esclarecido.

A forma epimastigota apresenta um ccmplexo de Golgi bastante evidente, sendo constituído por sáculos e vesículas que muitas vezes se dispóem de forma concêntrica (Fig. 4). Está localizado ao lado do cinetoplasto e próximo a região da bolsa flagelar e do citostomo tal como descrito anteriormente $(18,19)$. O citostomo representa uma estrutura especializada da superfície em que ocorre uma invaginação da membrana celular e dos microtúbulos subpeliculares (Fig. 3). Esta estrutura tem sido encontrada abrindo-se na regiāo da bolsa flagelar ou antes da curvatura da membrana celular que dá origem à formação da bolsa flagelar .Em ambos os casos é nítida a sua relação topográfica com o complexo de Golgi. Admite-se que o citostomo esteja envolvido no processo de ingestão de material nutritivo. No caso das formas epimastigotas do $T$. cruzi as evidências são indiretas e se baseiam principalmente no fato de que vesículas pinocitóticas estão associadas a esta estrutura. Um estudo em que se utilizam traçadores deve ser realizado com o $T$. cruzi afim de esclarecer melhor o papel funcional desta estrutura. Com as formas intracelulares em cultura de tecicios demonstrou-se que o $T$. cruzi é capaz de ingerir elementos citoplasmáticos da célula hospedeira, como por exemplo grânulos de melanina que são estruturas com cerca de $0,7 \mu \mathrm{m}$. Esse fato sugere que o T. cruzi apresenta um processo de fagotrofia intracelular à semelhança do que ocorre com os parasitos da malária, na fase eritrocitária $(18 ; 23)$.

Uma organela circular, delimitada por membrana e com uma matriz uniforme, é também encontrada na forma epimastigo- 
ta do $T$. cruzi. Tal organela apresenta um diâmetro de aproximadamente $0,6 \mu \mathrm{m}$. Seu aspecto é semelhante ao descrito em $T$. brucei, T. equiperdum, Crithidia fasciculata, Herpertomonas muscarum e Leptomonas pessoai como "peroxisome-like organelle" $(1,2,4,10,20,29)$. Estudos citoquímicos estão sendo realizados afim de esclarecer melhor a natureza desta estrutura.

No citoplasma do $T$. cruzi observa-se grande número de vacúolos, que apresentam dimensões variadas, senđo encontrados muitos com cerca de $07 \mu \mathrm{m}$ de diâmetro. São delimitaảos por membrana e apresentam no seu interior áreas de grande eletrodensidade bem como áreas de de pouca eletrodensidade (Figs. 1 e 5). Também observamos outras estruturas com perfil circular, envolvidas por membrana e eletrodensas (Fig, 2, 4 e 5). Estruturas semelhantes foram descritas por Wery \& Lasseel (32) como corpos multivesiculares. No entanto, nessas estruturas não se observou a presença de fosfatase ácida.

A natureza dessas estruturas ainda não está bem definida. Quando se aplica a técnica de Thiéry observa-se uma reação positiva em todo o sistema superficial de membranas, o que inclui a membrana que envolve o corpo, a região da bolsa flagelar e o flagelo. Tal resultado indica a presença de carbohidratos constituintes do "cell coat" semelhante ao descrito para as formas em cultura de tecidos (7). No entan- to observamos que a membrana que envolve os vacúolos acima referidos também apresenta uma reação positiva semelhante à observada na membrana celular (Fig. 6 e 7). Uma reação positiva foi também encontrada nas membranas que constituem o complexo de Golgi. É possível Gue os vacúolos representem uma estrutura formada por vesículas pinocitóticas que se fundem, a fim cie formar um "food-vacuole" que posteriormente evolua para lisossomos. Estudos citoquímicos para detecção de fosfatase ácida bem como o uso de traçadores como ferritina e peroxidase estão sendo empregados afim de esclarecer a natureza e papel funcional destes vacúolos na forma epimastigota do $T$. cruzi.

\section{AGRADECIMENTOS}

Ao Dr Raul Dodsworth Machado pela contribuição prestada durante a realização deste trabalho e preparo do manuscrito. Ao Sr. Antonio L. de Oliveira pelos auxílios e a Srta. Sanaira C. de Carvalho pelo trabalho de datilografia.

Ao Conselho de Ensino Para Graduados da U.F.R.J., Conselho de Aperfeiçoamento do Pesscal de Nivel Superior (CAPES), Conselho Nacional de Desenvolvimento Científico e Tecnológico (CNPq) e Banco Nacional do Desenvolvimento Econômico (BNDE-Contrato Funtec-241) pelos auxilios concedidos ao Laboratório de Microscopia Eletrônica do Instituto de Biofísìca - U.F.R.J.

\section{SUMMARY}

In this paper the fine structure of the epimastigotes forms of Trypanosoma cruzi maintained in an acellular culture medium, is described.

During division the nucleus shows a homogenous structure owing to the dispersion of its chromatin and nucleolar material. Microtubules similar to those of a mitotic spindle in metazoan cells appear, running from one pole to the other. During the whole process of division the nuclear membrane remains intact.

The cytoplam shows many vacuoles. With the cytochemical method of acid periodic-thiosemicarbazide-silver proteinate, a polysaccharide surface coat is observed on the whole surface membrane system of $\mathrm{T}$. cruzi. A positive reaction is also observed in the membranes of some vacuoles in the cytoplasm of the parasites. 


\section{REFERÊNCIAS BIBLIOGRÁFICAS}

1. BAYNE, R. A., MUSE, K, E, \& ROBERTS, J. F. - Regulation of oxidase enzyme systems in trypanosomes. Comp. Biochem. Physiol 30: 61-72, 1969 .

2. BAYNE, R. A., MUSE, K. E. \& ROBERTS, J. F Isolation of bodies containing the cyanide-insensitive glycerol-phophate oxidase of Trypanosoma equiperdum. Comp. Biochem. Physiol, 30: 1049-1054. 1969.

3. BRACK, C. - Electronem mikroskopische Untersuchungen zum Lebenszyklus von Trypanosoma cruzi. Acta Tropica 25: 289-356, 1968.

4. BRUN, R. - Ultrastruktur und Zyklus von Herpetomonas muscarum, Herpetomonas mirabilis und Crithidia luciliae in Chrysomia chloropyga. Acta Trop., 31: 219-290, 1974.

5. CAMARGO, E. P. - Growth and differentiation in Trypanosoma cruzi. I Origin of metacyclic trypanosomes in liquid media. Rev. Inst. Trop. São Paulo, 6: 93-100 1964.

6. DE SOUZA, W. \& MEYER, H. - On the fine structure of the nucleus in Trypanosoma cruzi in tissue culture forms. Spindle fibers in the dividing nucleus. J. Protozool. 21: 48-52, 1974.

7. DE SOUZA, W. \& MEYER, H. - An Electron Microscopical and Cytochemical study of the cell coat of Trypanosoma cruzi, in tissue cultures. $Z$. Parasitenk, 1975 "in press".

8. DE SOUZA. W. - Cytochemical detection of polysaccharides on the surface of Trypanosomatids. Trans. Roy. Soc. Trop. Med Hug, 1975 "in press".

9. DE SOUZA, W. - Associations membrane-microtubules chez Trypanosoma cruzi. J. Microscopie, "in press".

10. DE SOUZA, W., ROSSI, M. A., KITAJIMA, E. W., SANTOS, R. R. \& ROITMAN, I. An Electron Microscopic of Leptomonas pessoai Submetido para publicação.

11. INOKI, S., OZEKI, Y. \& KAMBARA, R. - Ultrastructural changes in the kinetoplast of Trypanosoma cruzi during transition of form in vitro. $B i-$ ken J. 14: 37-50, 1971.

12. MARIA, T. A., TAFURI, W. \& BRENER, Z. - The fine structure of dif. ferent bloodstream forms of Trypanosoma cruzi. Ann. Trop. Med. Parasit 66: 423-431, 1972.

13. MEYER, H. \& PORTER, K. R. - A study of Trypanosoma cruzi with the electron microscope. Parasitology, 44: 16-23, 1954.
14. MEYER, H., OLIVEIRA MUSACCHIO, M. \& ANDRADE MENDONÇA, I. Electron microscopic study of Trypanosoma cruzi in thin sections of infected tissue cultures and blood agar forms. Parasitology 48: 1-8, 1958.

15. MEYER, H. \& QUEIROGA, L. T. Submicroscopical aspects of Schizotrypanum cruzi in thin sections of tissue culture forms. J. Protozool. 7: 124-127, 1960.

16. MEYER, H. - The fine structure of the flagellum and kinetoplast chondriome of Trypanosoma (Schizotrypanum) cruzi in tissue culture. $J$. Protozool. 15s 614-621, 1978.

17. MEYER, H. - Further studies on the fine structure of the kinetoplast-chondriome of Trypanosoma (Schizotrypanum) cruzi in thin sections of infected tissue culture. Rev. Inst. Trop. São Paulo 11: 48-56, 1979.

18. MEYER, H. \& DE SOUZA, W. - On the fine structure of Trypanosoma cruzi in tissue culture of pigment epithelium from the chick embryo. Uftake of melanin granules $y$ the parasite. J. Protozool. 20: 590-593, 1973.

19. MILDER, R. \& DEANE, M. P. - The cytostome of Trypanosoma cruzi and T. conorrhini. J. Protozool. 16: 730$-737,1969$.

20. MUSE, K. E. \& ROBERTS, J. F. - Microbodies in Crithidia fascicu lata Protoplasma 78: 343-348, 1973.

21. OZEKI, Y., SOOKSRI, V., ONO, T. \& INOKI, S. - Studies on the ultrastructure of kinetoplasts of Trypanosoma cruzi and Trypanosoma gambiense by autoradiography and enzymatic digestion. Biken's J. 14: 97-118, 1971.

22. PEREIRA DA SILVA, L. H. \& NUSSENZWEIG, V. - Sobre uma cepa do Tripanosoma cruzi altamente virulenta para o camundongo branco. Folia Clin. Biol. São Paulo 20: 191-201, 1953.

23. RUDZINSKA, M. A. \& TRAGER, W. Intracellular phagotrophy by malaria jarasites: an electron microscope study of Plasmodium lophurae. J. Protozool. 4: 190-199, 1957.

24. SANABRIA, A. - Ultrastructure of Trypanosoma cruzi in mouse myocardium. I. Trypanosome form, Exp. $P a$ rasit. 14: 81-91, 1963.

25. SANABRIA, A. - The Ultrastructure of Trypanosoma cruzi. II. Crithidial and Leishmanial forms. Exp. Parasit. 15: 125-137, 1964. 


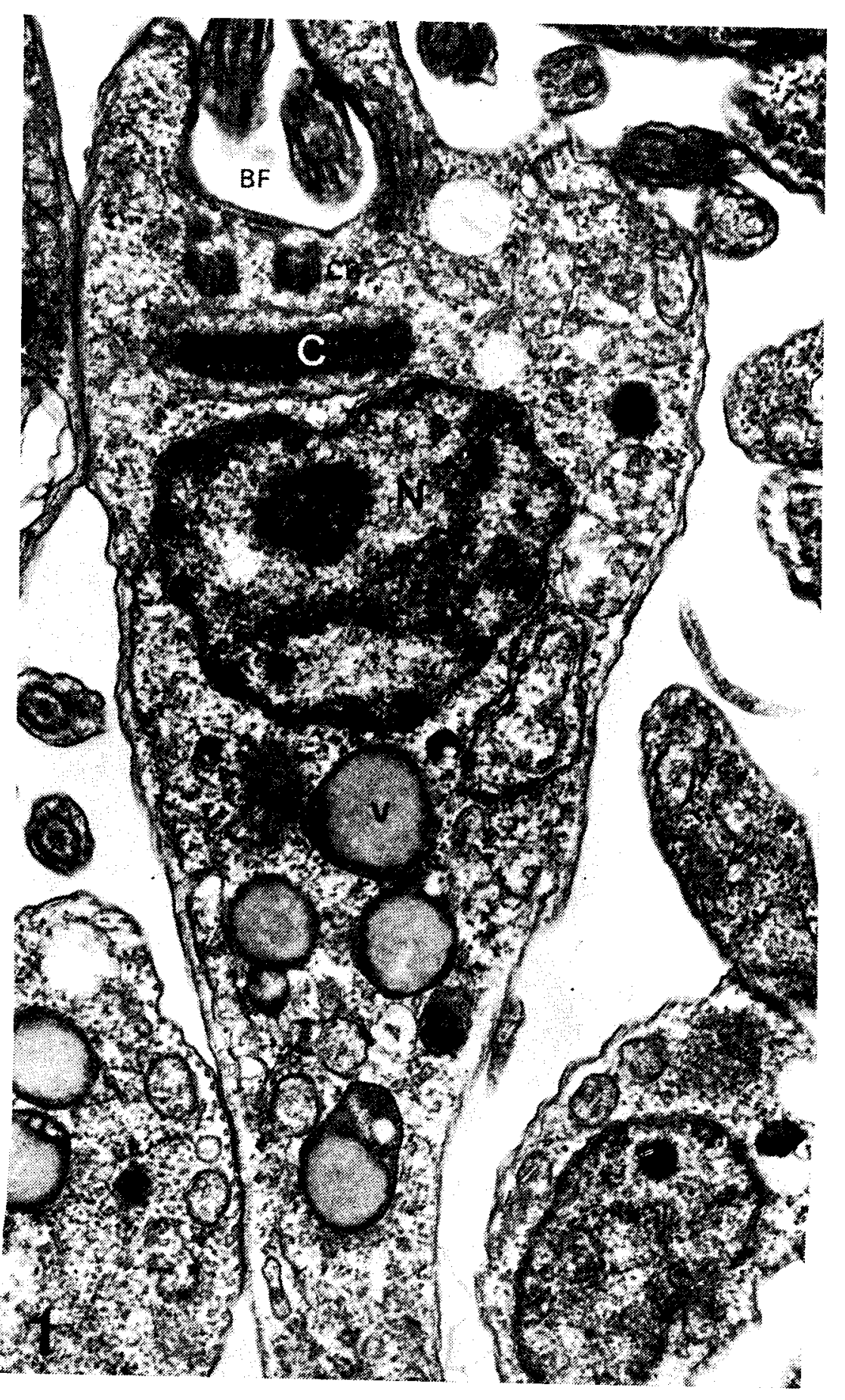


Fig. 1 - Epimastigota do T. cruzi. Observa-se o núcleo (N) de uma forma interfásica, contenco cromatina e o nucléolo (NU) . O cinetoplasto (C), parte do corpúsculo basal (CB) bem como a regiáo da bolsa flagelar (BF) são observadcs. Junto a núcleo e observaram vacúolos com vários aspectos (V). Microtúbulos são observados tanto em corte transversal como longitudinal.

X 10.000 

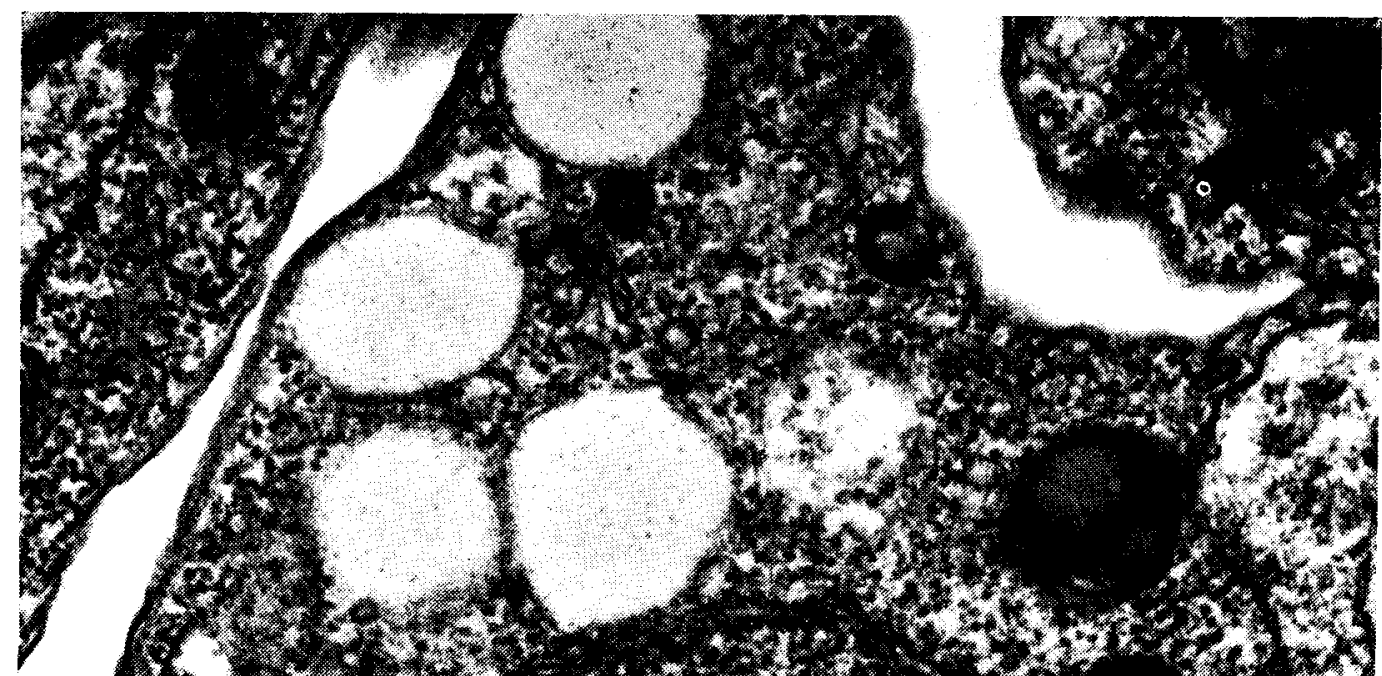

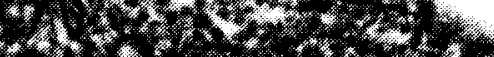
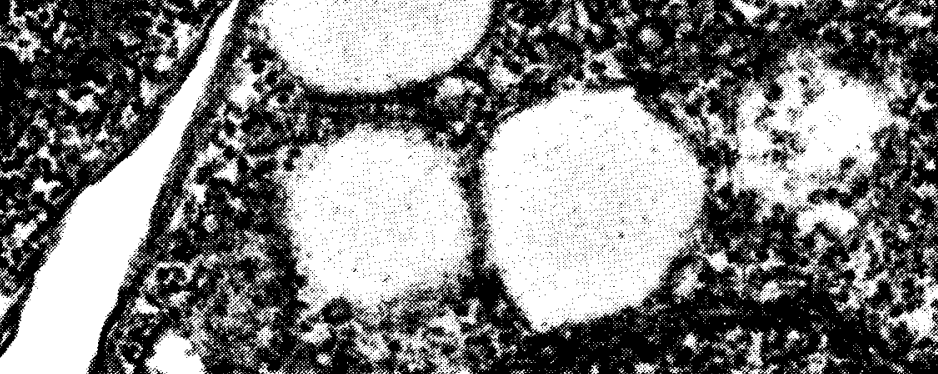

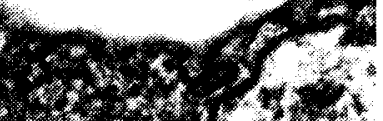

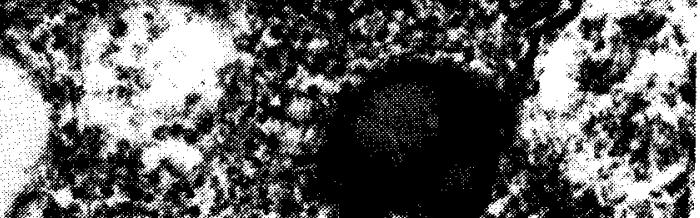

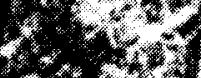

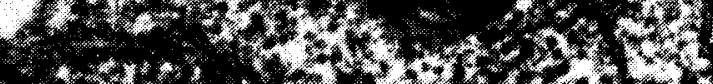
(2)

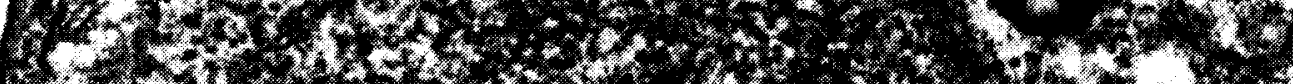

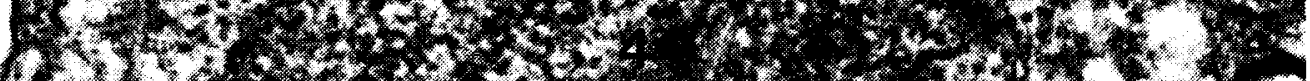

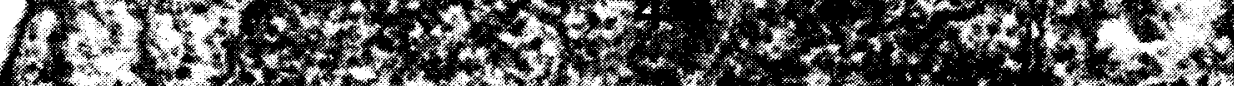

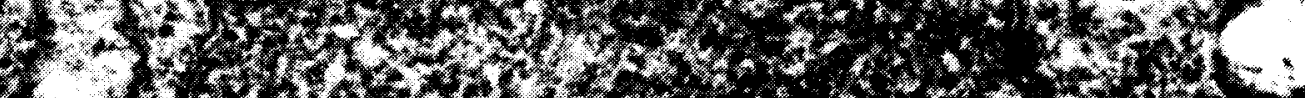

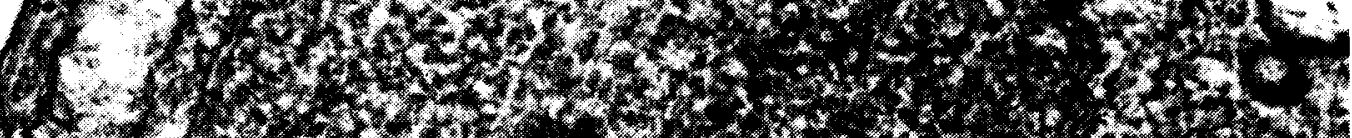

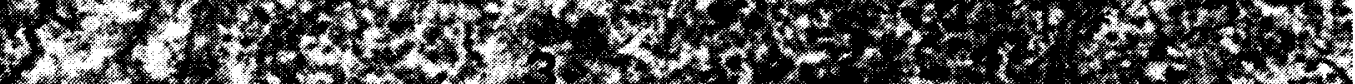

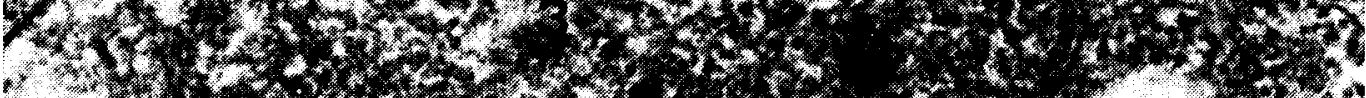

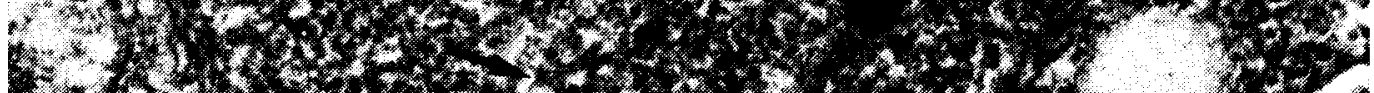

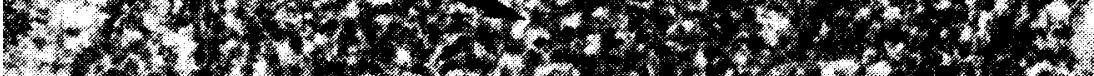
(f)

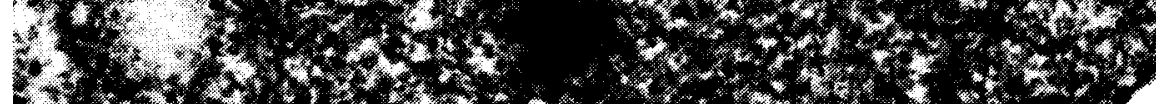

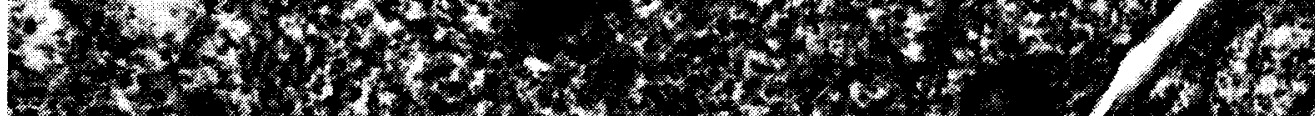

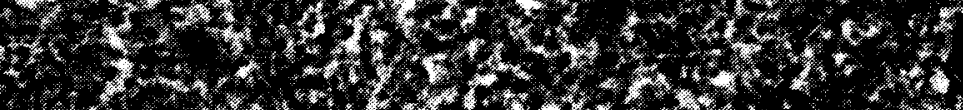

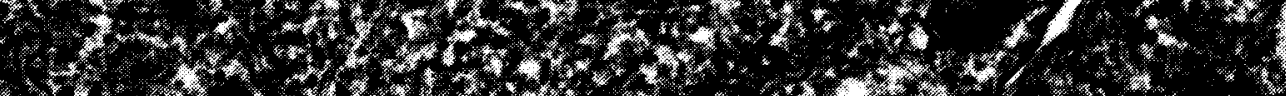

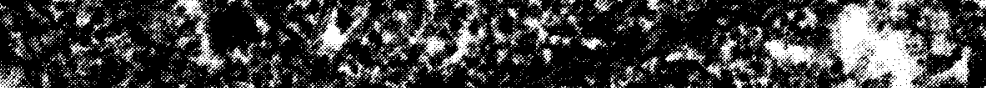

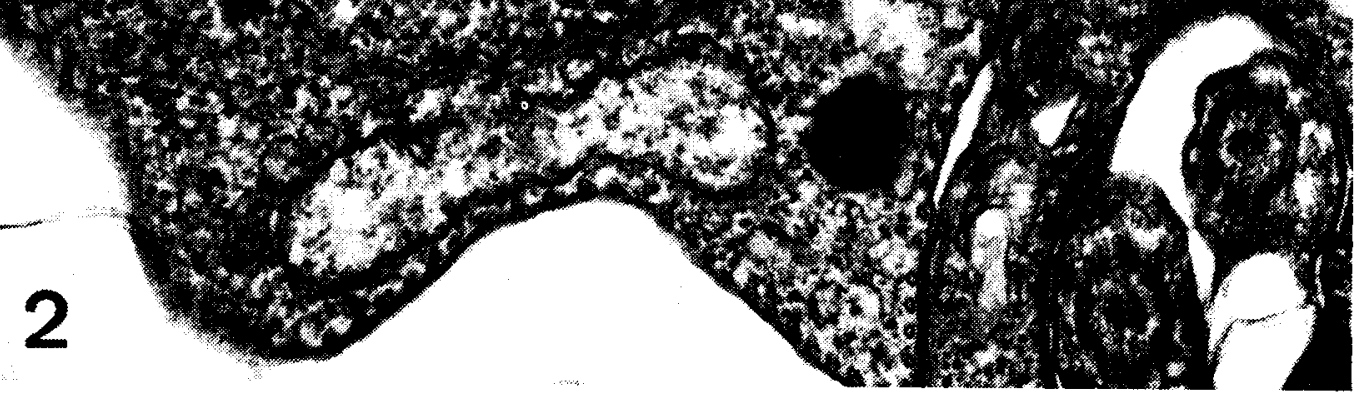


Fig. 2 - Parte de uma célula em divisão. O núcleo apresenta um aspecto uniforme. O material cromatínico e nucleclar não se encontra organizado. A membrana nuclear permanece integra. No interior do núcleo observa-se a presença de microtúbulos (seta) bem como 4 massas eletrodensas (1-4). X 45.000 
Fig. 3 - Detalre do citostomo (CT). Corresponde a uma invaginaçāo da membrana celular e dos microtúbulos subpeliculares (seta). Também se observa o corpúsculo basal (CB) e parte do cinetoplasto (C).

X 60.000

Fig. 4 - Parte do citoplasma mostrando a região do complexo de Golgi (G) que apresenta um aspecto concêntrico. Observam-se os sáculos e vesiculas constituintes cesta estrutura. $\mathrm{X} 45.000$ 


\section{7}
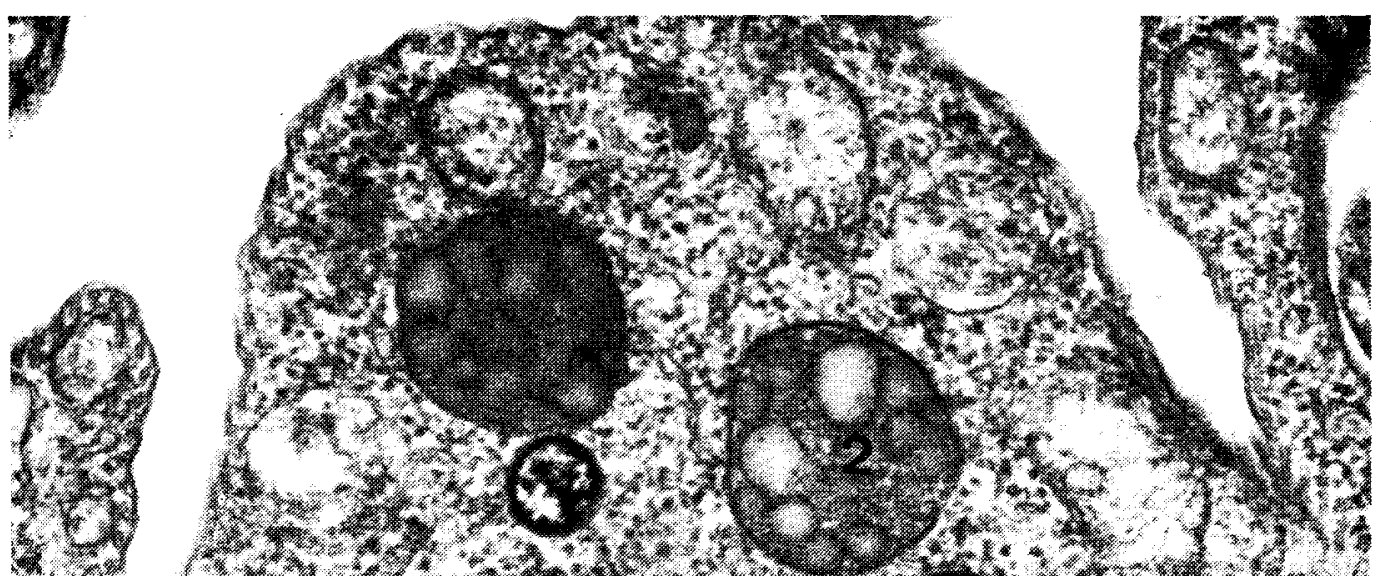

x.3.

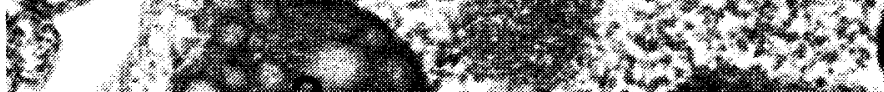

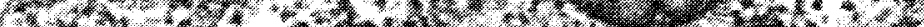

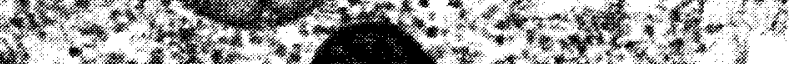

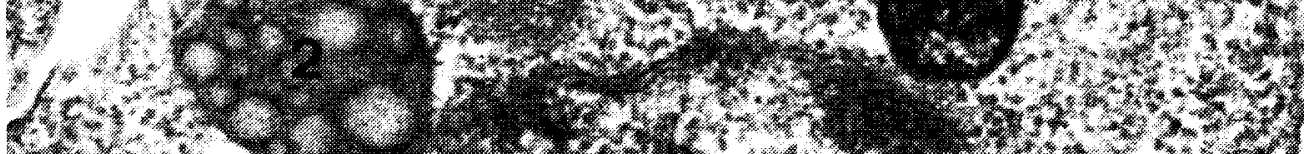

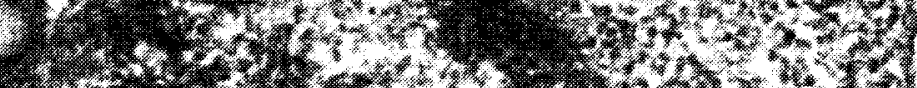

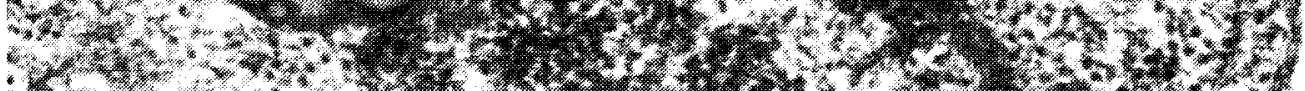

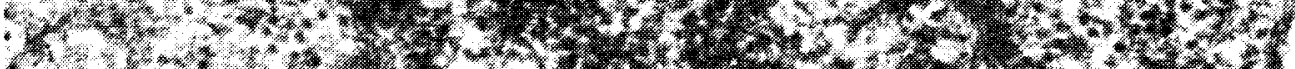

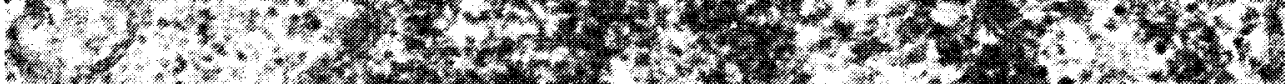

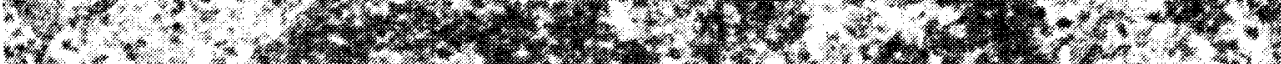

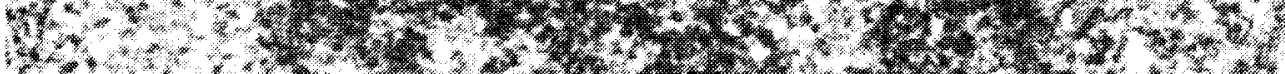

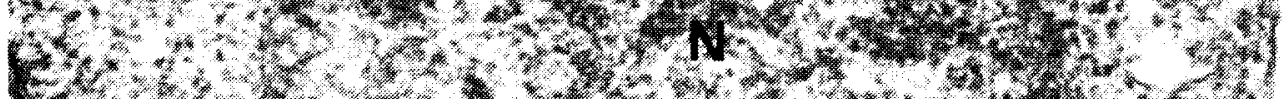

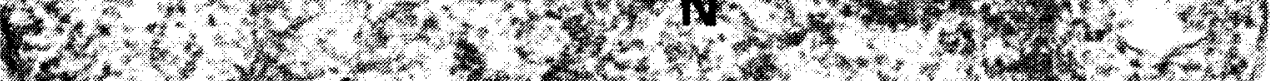

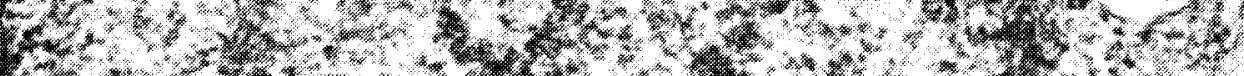

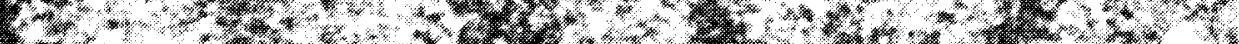

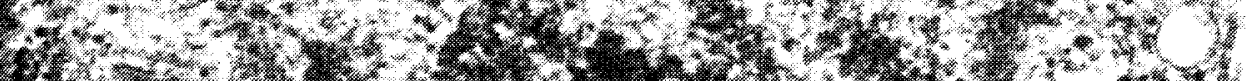

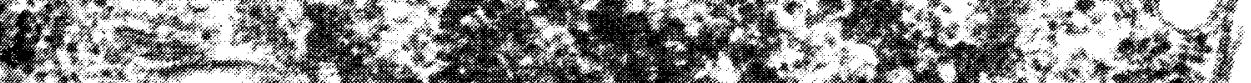

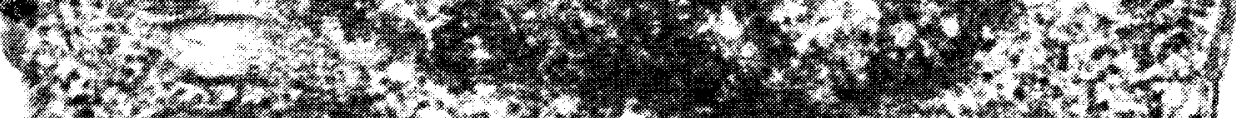

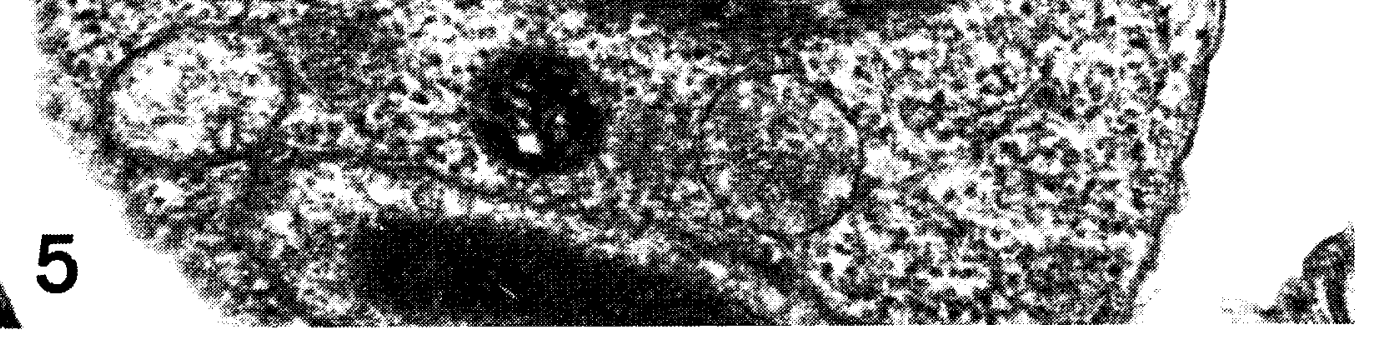

Fis. 5 - Parte do citoplasma mcstrando o núcleo (N) bem como alguns vacúólós. Estes pódem ser eletrdensos (1) ou de estrutura mais complexa (2). X 45.000 


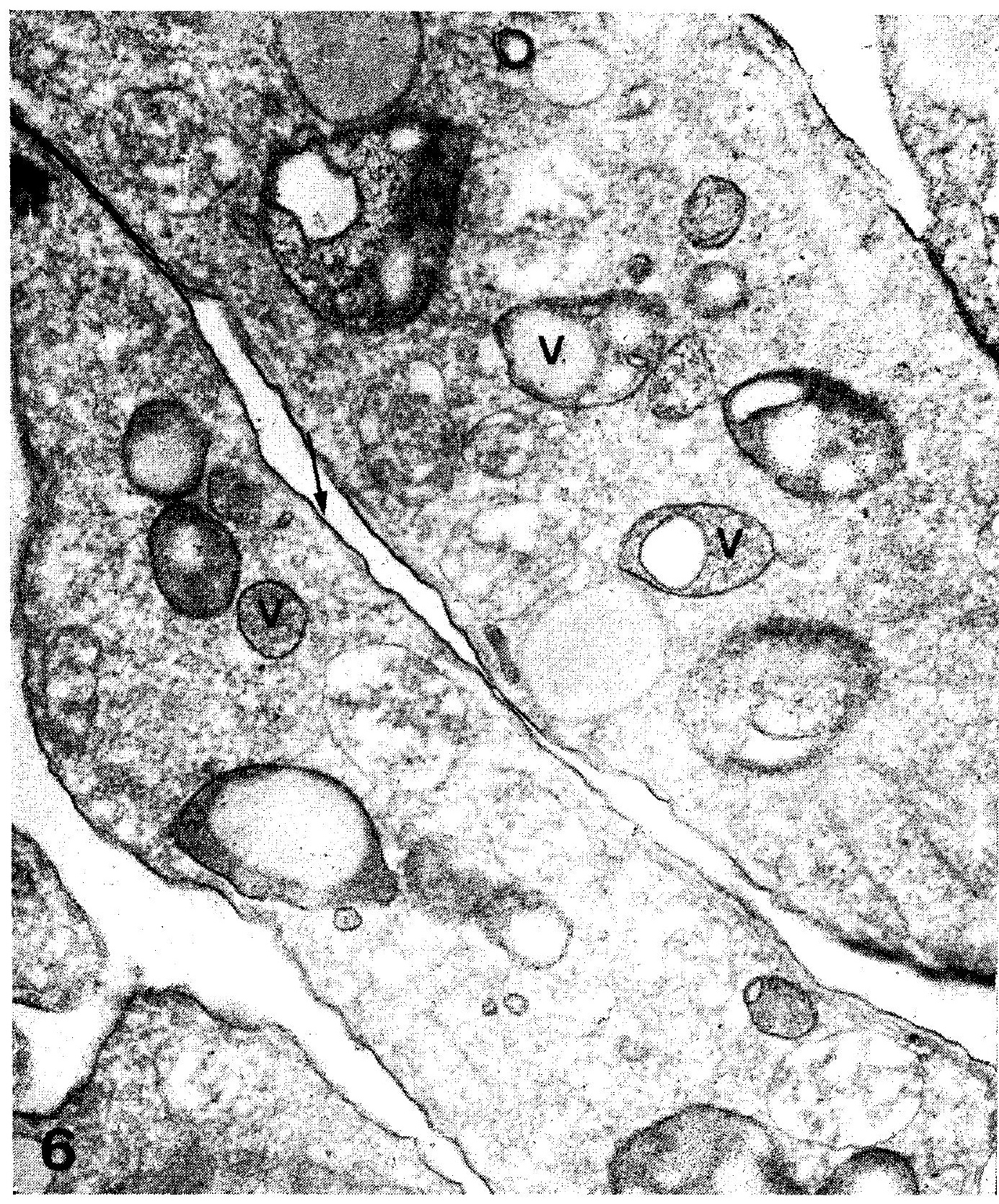

Fig. 6 - Corte näo contrastado pelo acetado de uranila ou citrato de chumbo. Submetido ao método de Thiéry com incubeçâo durante $78 \mathrm{hs}$ em tiosemicarbazida. Uma reaçăo positiva é observada na mebrana celular (seta) bem c cmo na membrana de determirados vácúolos citoplasmáticos $(\mathrm{V})$.

$\mathrm{X} 45.000$ 


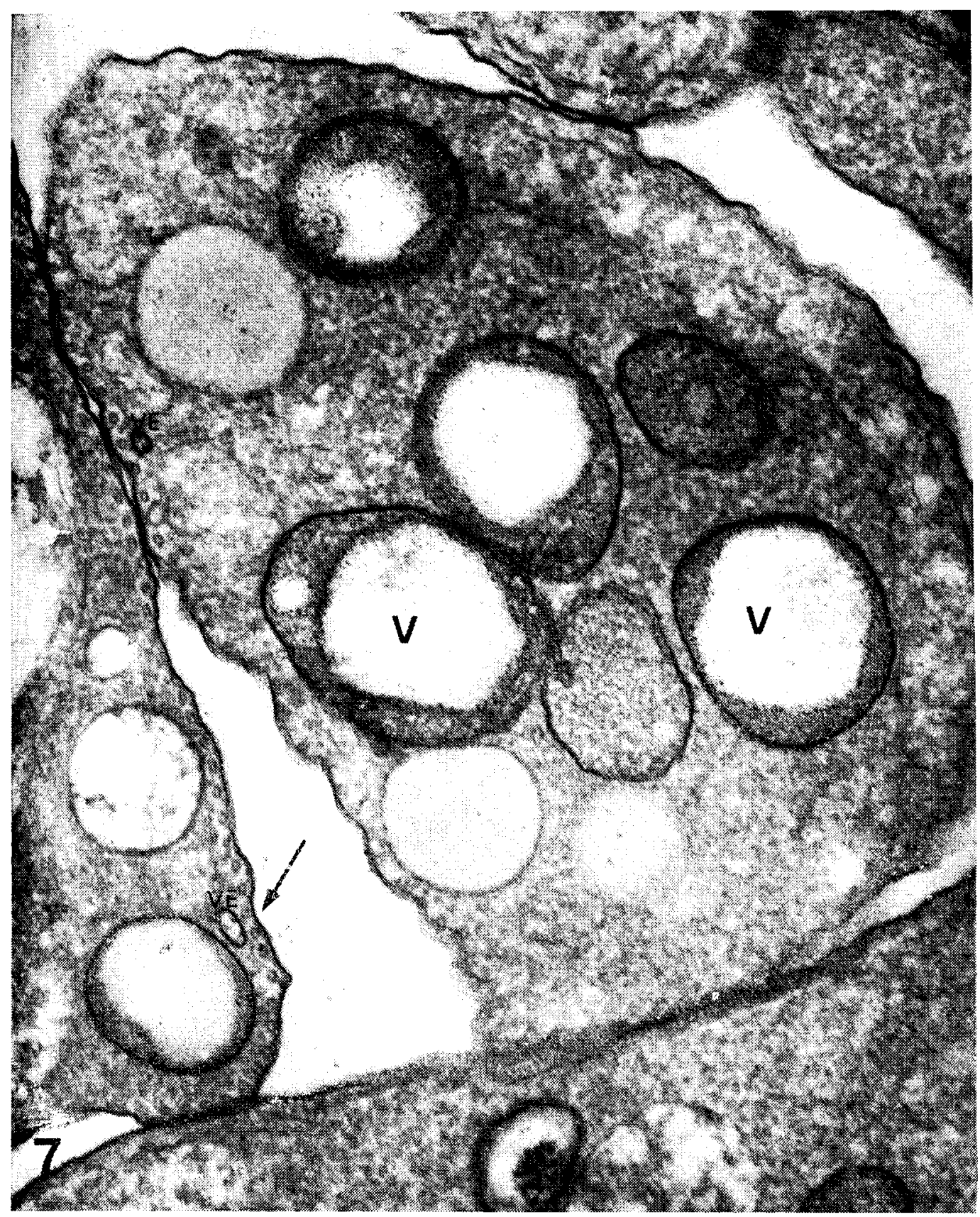

Fig. 7 - Corte não contrastado pelo acetado de uranila ou citrato de chumbo. Submetido as método de Thiéry com incubação durante $48 \mathrm{hs}$ em tiosemicarbazida. Uma reação positiva é cbservada na membrana celular (seta) bem com na membrana de detérminados vacúolos citoplasmáticos (V). Pequenas vesiculas lccalizadas na superficie celular (Ve) também reagem positivamente ì reação.

X 60.000 
26. SANABRIA, A. - Ultrastructure of Trypanosoma cruzi in mouse brain. Exp. Parasit. 23: 379-391, 1969.

27. SANABRIA, A. - Nuevos estudios acerca de la ultrastructure del Trypanosoma cruzi en el miocardio del raton. Acta Cient. Venezolana 21: 107$-118,1970$.

28. SCHULZ H. \& MACCLURE. E. Elektronenmikroskonische Untersuchungen des Trypanosoma cruzi mit besonderer Berücksichtigung des periplasten und des Blepharoplasten. Z. Zellforsch. 55: 389-412, 1961.

29. STEIGER, R. F. - On the ultrastructure of Trypanosoma (Trypanozoon) brucei in the course of its life cycle and some related aspects. Acta Tropica 30: 64-168, 1973.

30. THIÉRY, J. P. - Mise en évidence des polysaccharides sur coupes fines en microscopie electronique. J. Microscopie 6: 987-1018, 1967.

31. VICKERMAN, $K$ \& PRESTON, T. M. - Spindle microtubules in the dividing nuclei of trypanosomes. $J$. Cell Sci. 6: 365-383, 1970.

32. WÉRY, M. \& DE GROODT-LASSEEL, M. - Ultrastructure de Trypanosoma cruzi en culture sur milieu semisynthétique. Ann Soc. belge Méd. Trop. 46: 337-348, 1966 